\title{
Hemodynamic effects of right pelvic wedge in patients undergoing elective cesarean section under spinal anesthesia
}

\author{
Rohini Sigdel, Maya Lama, Sanish Gurung, Bishal Gurung, Anil Prasad Neupane, Asha Pun, Saindra Shrestha \\ All authors are affiliated to Department of Anesthesia, Pokhara Academy of Health Sciences (PAHS), Western \\ Regional Hospital, Pokhara Nepal
}

\section{Corresponding author: \\ Dr. Rohini Sigdel \\ Department of Anaesthesiology \\ Pokhara Academy of Health Sciences (PAHS), \\ Western Regional Hospital \\ Pokhara, Nepal}

Article recived : 15 th june 2018

Article accepted : 1st July 2018

\begin{abstract}
Background: Several methods have been used to prevent post spinal hypotension including preloading, co-loading, use of vasopressors, placement of pelvic wedge, lumbar wedge and tilting of operating table in parturients undergoing cesarean section. We conducted a randomized controlled study to determine the hemodynamic effects of a standard pelvic wedge placed below the right hip immediately after the spinal block till the delivery of baby.

Methods: One hundred consenting women undergoing elective cesarean section under spinal anesthesia were randomly allocated to wedge group $(\mathrm{N}=50)$ and control group ( $\mathrm{N}=50)$. A standard wedge was placed under the right pelvis soon after spinal anesthesia till the delivery of baby in wedge group whereas the control group remained supine. Hemodynamic parameters including blood pressure, heart rate, vasopressor consumption, other side effects like nausea, vomiting and neonatal outcome were also recorded. Results: The incidence of hypotension and bradycardia was similar between groups (Wedge group $60 \%$ vs Control group $75.51 \%, p=0.125)$ before the birth of baby. The use of vasopressors $(p=0.212)$, incidence of nausea $(p=0.346)$ and Apgar score at 1 and 5 minutes $(p=0.629, p=0.442)$ were also not statistically significant. None of the patients had vomiting.

Conclusion: In our study, the use of right pelvic wedge immediately after spinal anesthesia was not effective in preventing post spinal hypotension in elective cesarean section.
\end{abstract}

Key Words: Post spinal hypotension, cesarean section, pelvic wedge

\section{INTRODUCTION}

Hypotension remains one of the commonest complications following spinal anesthesia for cesarean section. ${ }^{1-2}$ Several efforts have been utilized to minimize post spinal hypotension including use of vasopressors, colloid preloading, crystalloid/ colloid coloading and various physical interventions. ${ }^{2-4}$ Use of different positions including full lateral, tilted supine, use of pelvic/lumbar wedge and different physical procedures like leg elevation, leg wrapping have been used in order to minimize aortocaval compression and increase central blood volume to prevent post spinal hypotension. ${ }^{5-10}$ Past and recent guidelines for obstetric anesthesia has recommended use of uterine displacement usually left, to be maintained until delivery regardless of the anesthetic technique. ${ }^{3,11,12}$ 
However, an investigation into the short term outcome of term neonate of mothers who had significant hypotension during elective cesarean section did not reveal major sequelae. ${ }^{13}$

In our centre, we routinely practice supine position and some anesthesiologist prefer left lateral tilting of bed. We hypothesized that a standard pelvic wedge placed below the right hip immediately after the spinal block till the delivery of the baby could reduce the incidence of post spinal hypotension.

\section{MATERIALS AND METHODS}

After ethical clearance from Institutional review committee, Pokhara Academy of Health Sciences (PAHS), Pokhara, 100 consenting parturients falling in inclusion criteria were randomized to one of the group: Wedge group (W) or Control group(C)

ASA II full term singleton parturients age 18 years to 40 years scheduled for elective cesarean section with height $150-165 \mathrm{~cm}$ and weight $45-90 \mathrm{~kg}$ were included.

Parturients with cardiovascular disease, hypertensive disorders of pregnancy, multiple gestation, hepatic disease, renal disease, and endocrine disease were excluded.

Baseline blood pressure and heart rate was measured in the waiting area preoperatively. All parturients received premedication with intravenous ranitidine $50 \mathrm{mg}$ and metoclopramide $10 \mathrm{mg} .18 \mathrm{G}$ intravenous cannula was secured and monitors were attached including non-invasive blood pressure (NIBP), electrocardiogram (ECG), pulse oximeter. Co-loading was done with crystalloid $10 \mathrm{ml} / \mathrm{kg}$. Spinal anaesthesia was performed in sitting position. $2 \mathrm{ml}$ hyperbaric bupivacaine $0.5 \%$ with $10 \mathrm{mcg}$ fentanyl $(0.2 \mathrm{ml})$ with total volume $2.2 \mathrm{ml}$ was administered via $25 \mathrm{G}$ Quincke spinal needle.

Immediately after spinal block patient were turned supine and wedge inserted below the right pelvis in Group W while the control group remained in supine position. The wedge used was wood with $10 \mathrm{~cm}$ height at outer edge, $12 \mathrm{~cm}$ width and 20 $\mathrm{cm}$ length. Oxygen was administered using simple facemask at the rate $4 \mathrm{~L} /$ minute to all the parturients. Blood pressure and heart rate were recorded every minute after the spinal block till the delivery of baby and then every 3 minutes till the end of the surgery. The time to reach T4 sensory block for pin prick was assessed and surgery allowed to proceed only when
T4 level was reached.

Maternal hypotension was defined as fall in mean blood pressure below $25 \%$ of the baseline and managed with injection mephentermine $6 \mathrm{mg}$ bolus. Bradycardia was defined as heart rate less than 50 beats per minute and managed with injection atropine $0.6 \mathrm{mg}$. Incidence of hypotension, bradycardia and use of vasopressor were recorded.

After the delivery of baby, wedge was removed and all parturients received injection oxytocin 5 units intravenous bolus.

Other side effects like nausea and vomiting were noted and managed accordingly.

Apgar score at 1 and 5 minutes were also recorded. The primary outcome of our study was incidence of hypotension and bradycardia after spinal block till delivery of baby. Secondary outcomes were use of vasopressors and incidence of adverse effects during surgery.

Data analysis was done using SPSS version 20.0 (SPSS, Chicago, IL, USA). Continuous data were expressed as mean \pm standard deviation (SD) or median (lower, upper quartile). Categorical data were presented as number (percentage). Independent t-test for normally distributed data and Mann-Whitney U-test for non-normally distributed data were used for comparison between two groups. Categorical data were compared using Chi-square test or Fisher's exact test wherever appropriate. $\mathrm{P}<0.05$ was considered to be statistically significant.

\section{RESULT}

A total of 100 patients were included in our study. Five parturients from wedge group were excluded due to difficulty in operation as complained by the surgeon and one from control group was excluded due to inadequate spinal anaesthesia. So, 45 patients of wedge group and 49 patients of control group were considered for analysis.

The age, weight and height of patients of the two groups were similar as shown in table 1.

\section{Table 1}

$\begin{array}{lccc} & \text { Wedge }(\mathrm{n}=45) & \text { Control }(\mathrm{n}=49) & \mathrm{p} \text {-value } \\ \text { Age (years) } & 26.04 \pm 3.966 & 26.22 \pm 4.823 & 0.845 \\ \text { Weight }(\mathrm{kg}) & 65.53 \pm 8.234 & 65.92 \pm 8.765 & 0.827 \\ \text { Height }(\mathrm{cm}) & 155(150-162) & 155(150-165) & 0.400\end{array}$

Data given as $n$, mean \pm SD or median (lower - upper quartile). 
Orginal Article Medical Journal of Pokhara Academy of Health Sciences (MJPAHS) Vol. 1 Issue 2 Jul-Dec 2018

Most common reason for elective cesarean section performed in our study population was previous cesarean section. (Table 2)

Table 2: Indications of Cesarean Section

$\begin{array}{lcccc}\text { Indication } & \begin{array}{c}\text { Wedge } \\ (\mathrm{n}=45)\end{array} & \begin{array}{c}\text { Control } \\ (\mathrm{n}=49)\end{array} & \text { Total } & \text { Percentage } \\ \text { 1. Previous Cesarean Section } & 21 & 12 & 33 & 35.11 \\ \text { 2. Failed induction } & 7 & 10 & 17 & 17.02 \\ \text { 3. Cephalo-pelvic disproportion } & 7 & 9 & 16 & 17.02 \\ \text { 4. Good size baby } & 3 & 7 & 10 & 10.64 \\ \text { 5. Oligohydramnios } & 3 & 3 & 6 & 6.38 \\ \text { 6. Oblique lie } & 1 & 4 & 5 & 5.32 \\ \text { 7. Breech } & 2 & 1 & 3 & 3.20 \\ \text { 8. Bad obstetric history } & 0 & 1 & 1 & 1.06 \\ \text { 9. Subfertility } & 0 & 1 & 1 & 1.06 \\ \text { 10. Transverse lie } & 0 & 1 & 1 & 1.06 \\ \text { 11. Premature rupture of } & 1 & 0 & 1 & 1.06 \\ \quad \text { membrane } & & & & \end{array}$

There was no significant difference in the interval between spinal anesthesia and attainment of T4 level block, spinal puncture to skin incision interval and spinal puncture to baby delivery time. The duration of surgery (interval between skin incision and skin closure) was significantly longer in the wedge group. (Table 3)

Table 3: Intraoperative characteristics

\begin{tabular}{|c|c|c|c|}
\hline Duration (minutes) & $\begin{array}{l}\text { Wedge } \\
(n=45)\end{array}$ & $\begin{array}{l}\text { Control } \\
(n=49)\end{array}$ & p-value \\
\hline 1. Spinal puncture to T4 level block interval & $5(2-8)$ & $4(2-14)$ & 0.105 \\
\hline 2. Spinal puncture to skin incision interval & $6(4-13)$ & $5(4-15)$ & 0.077 \\
\hline 3. Spinal puncture to birth of baby interval & $12(6-27)$ & $10(6-26)$ & 0.078 \\
\hline 4. Skin incision to skin closure interval & $93 \pm 7.665$ & $28.76 \pm 9.426$ & 60.021 \\
\hline
\end{tabular}

There was no significant difference in the incidence of hypotension before delivery of baby as well as during surgery in the two groups. (Table 4) One patient in the control group had bradycardia after delivery of baby.

Table 4: Incidence of hypotension, bradycardia

\begin{tabular}{|c|c|c|c|c|}
\hline \multirow{2}{*}{\multicolumn{2}{|c|}{ Before birth of baby }} & $\begin{array}{l}\text { Wedge } \\
(n=45)\end{array}$ & $\begin{array}{l}\text { Control } \\
(n=49)\end{array}$ & $p$-value \\
\hline & & & & \\
\hline 1. & Hypotension & $27(60 \%)$ & $37(75.51 \%)$ & 0.125 \\
\hline 2. & Bradycardia & 0 & 0 & \\
\hline \multicolumn{5}{|c|}{ During surgery } \\
\hline 1. & Hypotension & 37 (82.22\%) & $44(89.80 \%)$ & 0.374 \\
\hline
\end{tabular}

$\begin{array}{lllll}2 . & \text { Bradycardia } & 0 & 1(2.04 \%) & >0.05\end{array}$ Data represented as $\mathrm{n}$ (percentage).

The number of episodes of hypotension in the two groups before birth of baby is shown in fig. 1

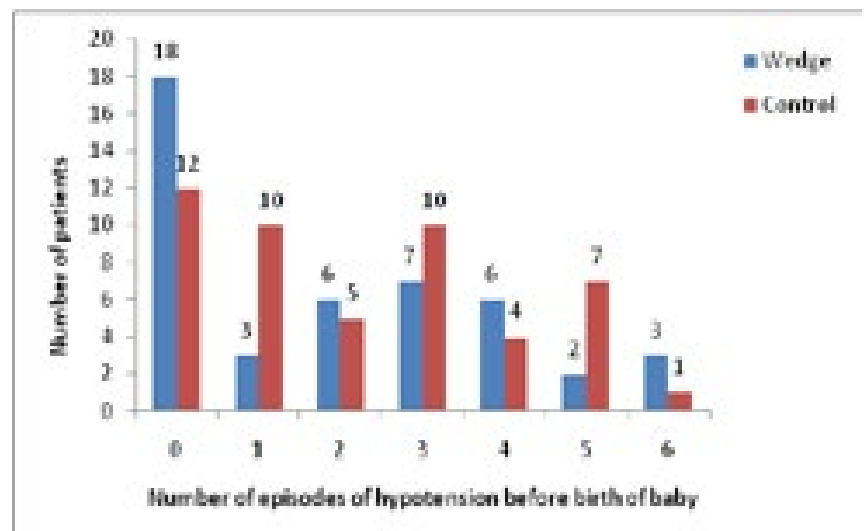

Fig. 1: Frequency of hypotension before birth of baby

The number of episodes of hypotension in the two groups during surgery is shown in fig. 2

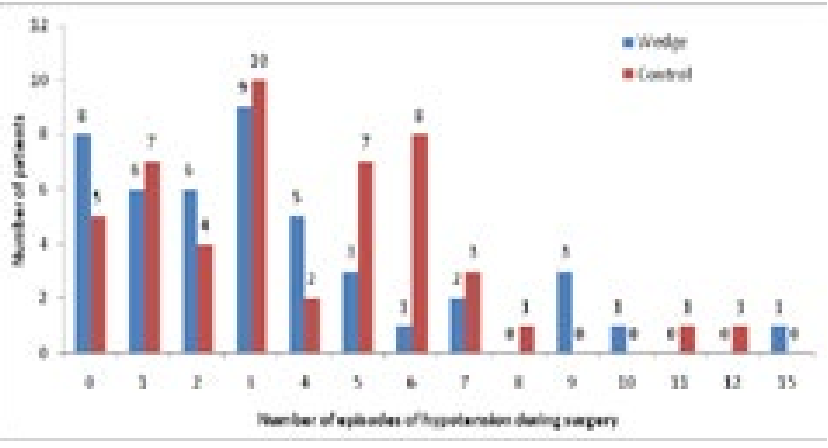

Fig.2: Frequencies of hypotension during surgery

Total dose of mephentermine and atropine used, incidence of nausea, vomiting and Apgar score of the newborn at 1 and 5 minutes after delivery was similar in patients of wedge and control group. (Table 5)

None of the patients had vomiting during surgery.

Table 5: Dose of mephentermine, atropine; Nausea, vomiting; Apgar score at 1 and 5 minutes

$$
\text { Wedge }(n=45) \quad \text { Control }(n=49) \quad p \text {-value }
$$

Dose of

$\begin{array}{llll}\text { 1. Mephentermine } & 18(0-90) & 18(0-72) & 0.212 \\ \text { 2. Atropine } & 0 & 0.6(0-0.6) & >0.05\end{array}$

Incidence of

$\begin{array}{lccc}\text { 1. Nausea } & 3 & 1 & 0.346 \\ \text { 2. Vomiting } & 0 & 0 & \\ \text { Apgar Score } & & & \\ \text { 1. At } 1 \text { minute } & 7(4-7) & 7(6-7) & 0.629 \\ \text { 2. At } 5 \text { minute } & 8(6-9) & 8(7-9) & 0.442\end{array}$

Data is represented as median (lower - upper quartile) 


\section{DISCUSSION}

The effect of different positions to prevent aortocaval compression before and after spinal anesthesia in maternal hemodynamics and block height has been studied in many previous studies. ${ }^{14-19}$ Stoneham et al utilized Oxford position while spinal anesthesia developed and showed the block to be more predictable and the patient hemodynamically stable. ${ }^{14}$ Rees et al compared arm and leg systolic pressure in parturients undergoing cesarean section with 15 degree left table tilt position and full left lateral position for a 15 minute period after spinal blockade. They showed significant decrease in mean leg systolic pressure in tilt group which revealed even a true 15 degree left tilt position was associated with aortic compression. ${ }^{17}$ Several studies have shown even the use of true left lateral position after spinal blockade didn't produce unilateral block but a block of slower onset with similar characteristics to the one in supine wedge position. ${ }^{15-16}$

In our study, we compared maternal hemodynamics in patients with pelvic wedge to that in supine position immediately after spinal block till delivery of baby. The total number of patients considered for analysis were 94 out of the 100 patients included. The demographic parameters were comparable between the groups. We used a wooden wedge with $10 \mathrm{~cm}$ height at outer edge, $12 \mathrm{~cm}$ width and $20 \mathrm{~cm}$ in length. Zhou et al used a wedge with $12 \mathrm{~cm}$ height either under the right pelvis or right lumbar region to prevent hypotension following combined spinal epidural (CSE) anesthesia for cesarean delivery. ${ }^{19}$ Lewis et al compared onset time of spinal block following CSE in cesarean delivery between full left lateral position and supine wedge position with pelvic wedge $10 \mathrm{~cm}$ in height immediately after the CSE which showed slower block onset in the lateral group. ${ }^{15}$

There was no significant difference in the interval between spinal puncture to attainment of T4 level block in our patients. Twenty seven patients $(60 \%)$ in wedge group and 37 patients $(75.51 \%)$ in control group had hypotension after spinal anaesthesia and before delivery of baby but this was statistically insignificant. Hence, it showed that use of right pelvic wedge was ineffective in preventing post spinal hypotension. In a study conducted by Calvache et al the use of right lumbar pelvic wedge was not effective in reducing the incidence of hypotension during spinal anesthesia for cesarean section. ${ }^{18}$ However, they used a lumbar pelvic wedge rather than a pelvic wedge. They used $0.5 \%$ hyperbaric bupivacaine $9 \mathrm{mg}$ with $20 \mathrm{mcg}$ fentanyl whereas we used $10 \mathrm{mg} 0.5 \%$ hyperbaric bupivacaine with $10 \mathrm{mcg}$ fentanyl.

Zhou et al compared lumbar wedge with pelvic wedge in preventing hypotension following CSE for cesarean delivery which revealed less incidence of hypotension in lumbar group than in pelvic group although it didn't eliminate hypotension. ${ }^{19}$

In our study, there was no episode of bradycardia in either group before the delivery of baby which is similar to study done by Zhou et al. ${ }^{19}$

The vasopressor used routinely in our practice is mephentermine as it is available as a part of safe motherhood package. Hence, we also recorded mephentermine consumption but there was no significant difference in mephentermine consumption between the groups. However, recent obstetric anesthesia guidelines recommends use of either intravenous ephedrine or phenylephrine for treating hypotension. ${ }^{3}$ Calvache et al revealed decrease consumption of ethylephrine in the lumbopelvic wedge group than in the supine group in their study. ${ }^{18}$

The consumption of ephedrine was also significantly lower in lumbar than the pelvic wedge group in study performed by Zhou et al. ${ }^{19}$

The incidence of nausea vomiting and the neonatal Apgar score at 1 and 5 minutes were similar in both the group in our study.

A recent review concluded that there is limited evidence to support or clearly disprove the value of the use of tilting or flexing the table, the use of wedges and cushions or the use of mechanical displacers. A left lateral tilt may be better than a right lateral tilt and manual displacers may be better than a left lateral tilt but larger studies with more robust data are needed to confirm these findings. ${ }^{12}$

Limitations:

Blinding was not possible as the anesthetist who measured the intraoperative hemodynamics could appreciate the presence of wedge. There are other measures of hemodynamics beside mean arterial pressure and bradycardia which could have been 
more reliable. Apgar scores were the only measures for neonatal outcome as the facility to determine umbilical arterial $\mathrm{pH}$ was not available.

\section{CONCLUSION}

In conclusion, the use of right pelvic wedge in our population undergoing cesarean section under spinal anesthesia was not effective in preventing post spinal hypotension. The risk of hypotension remains high.
Acknowledgement:

We would like to extend our sincere thanks to our obstetrician colleagues who co-operated with us during the entire study period.

\section{Conflict of interest}

None

\section{REFERENCES:}

1. Burns S.M, Cowan C.M WRG. Prevention and management of hypotension during spinal anaesthesia for elective Cesarean section: a survey of practice. Anaesthesia. 2001;56(8):794-8.

2. Mercier FJ, Augè M, Hoffmann C, Fischer C, Le Gouez A. Maternal hypotension during spinal anesthesia for caesarean delivery. Minerva Anestesiol. 2013;79(1):62-73.

3. Apfelbaum JL, Hawkins JL, Agarkar M, Bucklin BA, Connis RT, Gambling DR, et al. Practice Guidelines for Obstetric Anesthesia: An Updated Report by the American Society of Anesthesiologists Task Force on Obstetric Anesthesia and the Society for Obstetric Anesthesia and Perinatology. Vol. 124, Anesthesiology. 2016. 270-300 p.

4. Gurumeta AA, Vecino JMC. Colloids versus crystalloids in the prevention of cesarean section . A systematic review and metaanalysis. Minerva Anestesiol. 2015;81(9):1019-30.

5. Bamber JH, Dresner M. Aortocaval Compression in Pregnancy: The Effect of Changing the Degree and Direction of Lateral Tilt on Maternal Cardiac Output. Anesth Analg. 2003;97:256-8.

6. Morgan PJ, Tarshis J, Halpern SH. The Effects of an Increase of Central Blood Volume Before Spinal Anesthesia for Cesarean Delivery: A Qualitative Systematic Review. Anesth Analg. 2001;92(January):997-1005.

7. Law ACS, Lam KK, Irwin MG. The Effect of Right Versus Left Lateral Decubitus Positions on Induction of Spinal Anesthesia for Cesarean Delivery. Anesth Analg. 2003;97:1795-9.

8. Kundra P, Arunsekar G, Vasudevan A, Vinayagam S, Habeebullah S. Effect of postural changes on inferior venacava dimensions and its influence on haemodynamics during caesarean section under spinal anaesthesia Effect of postural changes on inferior vena cava dimensions and its infl uence on haemodynamics during caesar. J Obstet Gynaecol (Lahore). 2015;35(7):667-71.

9. Hasanin A, Aiyad A, Elsakka A, Kamel A, Fouad R, Osman M, et al. Leg elevation decreases the incidence of post-spinal hypotension in cesarean section : a randomized controlled trial. BMC Anesthesiol. 2017;17(60):1-6.

10. Mendonca C, Griffiths J, Ateleanu B, Collis RE. Hypotension following combined spinal-epidural anaesthesia for Caesarean section: Left lateral position vs. tilted supine position. Anaesthesia. 2003;58(5):428-31.

11. Kinsella SM, Whitwam JG, Spencer JA. Reducing aortocaval compression: how much tilt is enough? BMJ [Internet]. 1992;305(6853):539-40. Available from: http://www.ncbi.nlm.nih.gov/pmc/articles/PMC1883291/pdf/bmj00090-0009.pdf

12. Cluver C, Novikova N, Gj H, Cluver C, Novikova N, Hofmeyr GJ, et al. Maternal position during caesarean section for preventing maternal and neonatal complications ( Review) Maternal position during caesarean section for preventing maternal and neonatal complications. Cochrane database Syst Rev. 2013;(3):3-5.

13. Todris L, Etchin A, Kuint J. Maternal hypotension during elective cesarean section and short-term neonatal outcome. Am J Obstet Gynecol [Internet]. 2010;202(1):56.e1-56.e5.Available from: http://dx.doi.org/10.1016/j.ajog.2009.07.012

14. Stoneham M, Eldridge J, Popat M, Russell R. Oxford positioning technique improves haemodynamic stability and predictability of block height of spinal anaesthesia for elective caesarean section. Int J Obstet Anesth. 1999;8:242-8.

15. Lewis NL, Ritchie EL, Downer JP, Nel MR. Left lateral vs. supine, wedged position for development of block after combined spinalepidural anaesthesia for Caesarean section. Anaesthesia. 2004;59(9):894-8.

16. Hartley H, Seed PT, Ashworth H, Kubli M, O'Sullivan G, Reynolds F. Effect of lateral versus supine wedged position on development of spinal blockade and hypotension. Int J Obstet Anesth. 2001;10(3):182-8.

17. Rees SGO, Thurlow JA, Gardner IC, Scrutton MJL, Kinsella SM. Maternal cardiovascular consequences of positioning after spinal anaesthesia for Caesarean section: Left $15^{\circ}$ table tilt vs. left lateral. Anaesthesia. 2002;57(1):15-20.

18. Calvache JA, Muñoz MF, Baron FJ. Hemodynamic effects of a right lumbar-pelvic wedge during spinal anesthesia for cesarean section. Int J Obstet Anesth. 2011;20(4):307-11.

19. Zhou ZQ, Shao Q, Zeng Q, Song J, Yang JJ. Lumbar wedge versus pelvic wedge in preventing hypotension following combined spinal epidural anaesthesia for caesarean delivery. Anaesth Intensive Care. 2008;36(6):835-9. 